\title{
HORÁCIO COSTA
}

Horácio Costa constitui um daqueles casos particulares no domínio da tradução literária nacional. Além de tradutor, é poeta, ensaísta e professor de literatura. Traduziu nomes como César Vallejo, Elizabeth Bishop e Octavio Paz. É autor dos poemários Satori (1989), O menino e o travesseiro (1994) e Ciclópico olho (2011). Publicou individual e coletivamente vários volumes de ensaios, como A palavra poética na América Latina: avaliação de uma geração (1992), José Saramago: o período formativo (1997) e Mar aberto (2010). E ensina literatura portuguesa, desde 2001, na Faculdade de Filosofia, Letras e Ciências Humanas da Universidade de São Paulo. Horácio Costa, portanto, é um tradutor que possui uma experiência muito rica com a literatura. Nos últimos anos, ele vem traduzindo frequentemente autores de uma terra onde morou por muito tempo: o México. Lá, foi professor de literatura luso-brasileira na Faculdade de Filosofia e Letras da Universidade Nacional Autônoma do México, entre 1987 e 2001. Durante esse tempo, conheceu profundamente o sistema literário mexicano. Leu nomes seus do período pré-hispânico ao período contemporâneo. De volta ao Brasil, em 2001, Costa decidiu traduzir mais nomes desse sistema. Foi o caso de José Gorostiza (1901-1973), até então inédito em língua portuguesa. Gorostiza foi um poeta de produção exígua. Sua obra é composta basicamente por dois poemários: Canciones para cantar en las barcas (1925) e Muerte sin fin (1939). Mas esse último foi o bastante para sua canonização na literatura mexicana. Nele, o ser poético transita por uma monumental arquitetura da morte. Em dez extensas e pomposas partes, ele busca compreender seus diversos espaços. A tradução de Gorostiza foi publicada, em 
2003, pela Editora da Universidade de São Paulo e pelo Fundo de Cultura Econômica, numa edição bilíngue espanhol-português. Na presente entrevista, Horácio Costa fala a respeito dela e também da tradução da literatura mexicana no Brasil. Ele discorre, por exemplo, sobre o ato de traduzir o importante poema "Muerte sin fin" e sobre o estado da tradução de autores mexicanos hoje no país.

Geylson Alves

UFCG

Cadernos de Tradução (CT) - Qual é a situação atual da tradução da literatura mexicana no Brasil?

Horácio Costa $(H C)$ - O México está num lugar contraditório para nós. Por fazer parte da América do Norte, e de estar bastante longe do Brasil, diga-se de passagem (a Cidade do México está mais longe de São Paulo, por exemplo, do que Nova Iorque), os autores mexicanos não gozaram da voga que a literatura hispanoamericana dos nossos vizinhos imediatos tiveram por aqui, nos anos 60 e nas décadas seguintes. Há uma exceção na prosa - Juan Rulfo - e uma na poesia, Octavio Paz. Entretanto, os demais grandes nomes mexicanos não existem em português como nomes canônicos. Mesmo Paz é mais conhecido e admirado como poeta crítico, i.e., mais a partir de seus livros de crítica do que de seus livros de criação literária. Basta dizer que, nas últimas décadas, apenas o Haroldo de Campos e eu traduzimos poemas seus Transblanco e Piedra de Sol, respectivamente, ambas as traduções da década dos 80. E depois está o meu Gorostiza. Traduzi alguns outros dos participantes de "Contemporáneos", uma geração muito interessante e sobre a qual já dediquei alguns ensaios, e a Editora Lumme irá publicar no ano que vem a minha tradução completa de Xavier Villaurrutia, um desconhecido entre nós. 
CT - Qual é a recepção da tradução de autores mexicanos no país?

$H C$ - Não é necessário dizer que é pequena. Entretanto, você leu o meu Gorostiza e se interessou por ele e me está fazendo esta entrevista sobre sua obra. A minha tradução de Piedra de Sol, publicada originalmente em 1988 pela Guanabara e há muito esgotada, teve uma segunda edição há dois anos, pela Annablume; o Transblanco haroldiano também já foi reeditado. É algo: há leitores, portanto.

CT - Por que razão traduziu o mexicano José Gorostiza?

$H C$ - Por um lado, porque me interessa a sua poesia. Por outro lado, porque o poema "Muerte sin fin", importantíssimo para o universo da poesia hispano-americana do século passado, simplesmente não existia em português antes da minha tradução. Eu tenho curiosidade sobre como escrevem os meus vizinhos culturais. Admirava o poema e o poeta, por várias razões, e resolvi oferecê-lo aos leitores brasileiros.

CT - O editor interferiu de algum modo em sua tradução de Gorostiza?

$H C$ - Não. Ele nem sabia que o poeta existia.

CT - Por que motivo sua tradução de Gorostiza foi publicada no formato bilíngue? Tradução bilíngue contribui para a visibilidade do tradutor?

$H C$ - Eu prefiro que minhas traduções sejam sempre bilíngues. A experiência de leitura da poesia não é a da prosa ou a do ensaio, e 
nela a questão da língua joga um papel maior. Daí, o oferecer ao leitor essa experiência completa me parece o mais ético e prazeroso a fazer.

CT - Qual foi seu objetivo ao escrever um prólogo à tradução de Gorostiza? Tradução prologada estabelece direta ou indiretamente um contrato de leitura com o leitor?

$H C$ - O poeta, o leitor e eu merecíamos esse contato/contrato. Tenho a esperança de que o leitor não pense que o prólogo está abaixo do nível do poema. Corri o risco e não me arrependo.

CT - Na tradução do poema "Se alegra el mar", por que razão o senhor traduziu o vocábulo "roja" por "roxa", e não por "vermelha"? O fônico deve primar sobre o semântico na tradução poética?

$H C$ - Penso que não há regras no que se refere à tradução poética. Também traduzi "amarelos" por "jalnes", em outro poema. E na minha tradução de "Piedra de Sol", de Octavio Paz, começo o longuíssimo poema por traduzir uma árvore por sua família botânica: "sauce" por "sálix". O Haroldo gostou bastante desta minha ousadia. O Paz aprovou-a. Se tivesse traduzido a palavra por "chorão" ou "salgueiro"... pois bem, não seria bem eu, entende? A primeira palavra corresponde perfeitamente ao nome completo em espanhol, "sauce-llorón", só que eles mantiveram a primeira parte do conceito e não a segunda, e nós esquecemos aquela e ficamos com esta. Então, resolvi chamá-la de volta, através do latim, e assim não quebraria a métrica que tratei de manter o mais integralmente na tradução do poema. Em resumo, supervalorizar só o fônico é preciosismo. Tem que ter um lastre, senão vira uma demonstração de imodéstia tradutora. Os textos poéticos têm 
ritmo; porque as línguas também conhecem ritmos que lhes são próprios e porque as línguas literárias de cada língua criam formas que passam a ser naturais na dicção dos povos e, mesmo, às vezes, passam a representá-los; e os versos, muitas vezes têm métrica, porque a estesia do dizer específico daquele poema o exige, muito provavelmente em contato com esse "arquivo" do dizer poético ao que me acabo de referir. Uma sílaba pode, portanto, fazer muita diferença. Se há equivalentes, porque não usá-los? "Jalne" é a cor amarela em heráldica, e vermelho em espanhol não era exatamente "rojo", mas "bermejo"... na Idade Média. Então, a licença em traduzir "rojo" por "roxo" resgata esse espelhamento interibérico, em outro ponto do espectro das cores...

CT - Na tradução do poema "La casa del silencio", por que motivo o senhor recriou a sintaxe dos versos "y la oigo verter con un ruido / ya casi imperceptible, contenido, / su lloro paternal de tres mil años" ao traduzi-los por "e ouço-a verter com um ruído / quase imperceptivel já, contido, / seu choro paternal de três mil anos”? Tradução é recriação?

$H C$ - Não foi recriação de sintaxe, mas de acentuação. É uma questão de oitiva interna, um tema auricular, por assim dizer. É sim, tradução é recriação.

CT - Na tipografia da tradução do poema "La orilla del mar", o revisor de provas deixou escapar erros? Erros tipográficos incomodam o tradutor?

$H C$ - I could not spot any (big) trouble there.

CT - Comente um pouco sua experiência de traduzir o célebre poema "Muerte sin fin". 
$H C$ - Interessam-me os poemas longos porque os escrevo. Interessam-me o barroco e o neobarroco porque vejo aí uma origem muitas vezes escamoteada de nosso ser histórico atual, e que me atrai por razões temperamentais. Interessa-me o dizer complexo. "Less is more" é uma convenção da técnica para fazer passar um conceito dominante de cultura, afinado com o capitalismo triunfante de há cem anos, circa. O exagero diccional de "Muerte sin fin" me fascinou desde a primeira vez que o li. Mas não é apenas no nível da linguagem que ele me interessa: também no que se refere ao tópico mortuário. Nosso grande poema neobarroco, "Invenção de Orfeu", vai por outro lado e encontra o Brasil que não apenas Jorge de Lima trata de nomear, mas que Sérgio Buarque de Holanda estuda, como enteléquia, no espírito e na cultura ocidentais. "Muerte sin fin" vai para trás, para o substrato mortuário tão presente na cultura mexicana e pré-colombiana, de um modo geral. Ou seja, o texto era um desafio cultural, além de linguístico. Foi difícil traduzi-lo, mas também um prazer. Além do que, eu vivi 14 anos no México, e li os grandes nomes da literatura novo-hispana e mexicana com afinco... Gorostiza conversa com Sóror Juana e com Octavio Paz, dois poetas que me interessam muito. E com Ramón López Velarde, a quem estou tratando de traduzir, e com Villaurrutia, cuja obra já traduzi, como disse.

CT - Qual foi o maior desafio que a tradução de Gorostiza lhe apresentou?

$H C$ - O maior foi de ordem cultural. O tom de Gorostiza, entre solene e íntimo, não confere com a nossa retórica informalizante e avessa à solenização, instaurada na cultura brasileira a partir do nosso Modernismo. Vários hispano-americanos, se mal traduzidos, poderão parecer em português ossificados, mesmo pernósticos, ao passo que não soam assim em suas culturas de origem. Traduzir do espanhol - ou, melhor dizendo, das diferentes correntes poéticas que se afirmaram na poesia de língua espanhola a partir de finais do 
séc. XIX -, é um desafio para o brasileiro, que tende a uniformizar a América Latina em uma mesma cultura. Não é fácil traduzir do(s) hispano-americano(s) ao português brasileiro, em resumo. Ao contrário do que pensam os editores e os críticos/resenhistas de jornal no Brasil, isso exige não apenas muito trabalho, mas muita exposição ao outro e a si próprio, porque é sempre uma tradução crítica, de nossa língua e modo de ser e, portanto, de nós enquanto tradutores. Não sei se me faço entender.

CT - O senhor gostaria de rever algo da tradução de Gorostiza?

$H C$ - Não. Quando termino uma obra, viro a página. Senão, ficaria cozinhando os meus textos mais tempo. Um livro de poesia por mim publicado vai ao público em seu estado final. Isso é válido para todas as obras por mim autorizadas, sem exceção.

Entrevista concedida a Geylson Alves

UFCG 


\section{ANEXO}

\section{Criação literária}

28 poemas 6 contos. São Paulo: Editora do Autor, 1981.

Satori (poemas). São Paulo: Iluminuras, 1989.

O livro dos fracta. São Paulo: Iluminuras, 1990.

The very short stories. São Paulo: Iluminuras, 1991.

Quadragésimo. São Paulo: Ateliê, 1999.

O menino e o travesseiro. São Paulo: Geração, 2003.

Paulistanas/Homoeróticas. São Paulo: Lumme, 2007.

Ravenalas. São Paulo: Demônio Negro, 2008.

Quatro poemas brasileiros. São Paulo: Centro Cultural São Paulo, 2011.

Ciclópico olho. São Paulo: Annablume, 2011.

\section{Tradução literária}

Pedra do sol, de Octavio Paz. Rio de Janeiro: Guanabara, 1988. Poemas, de Elizabeth Bishop. São Paulo: Companhia das Letras, 1990.

Poemas humanos, de César Vallejo. Rio de Janeiro, Lisboa: O Globo, Diário de Notícias, 1992.

Águia ou sol?, de Octavio Paz. Rio de Janeiro: O Globo, 1994. Nostalgia da morte, de Xavier Villaurrutia. Lisboa: Diário de Notícias, 1994. 


\section{Ensaio}

A palavra poética na América Latina: avaliação de uma geração (Org.). São Paulo: Fundação do Memorial da América Latina, 1992.

José Saramago: o período formativo. Lisboa: Caminho, 1997.

Retratos do Brasil homossexual: fronteiras, subjetividades e desejos (Org.). São Paulo: Editora da Universidade de São Paulo, 2010.

Mar aberto. São Paulo: Lumme, 2010. 